\title{
Predictive value of coronary calcifications for future cardiac events in asymptomatic patients with diabetes mellitus: A prospective study in 716 patients over 8 years
}

\author{
Alexander Becker*1, Alexander W Leber ${ }^{1}$, Christoph Becker ${ }^{2}$, Franz von \\ Ziegler ${ }^{1}$, Janine Tittus ${ }^{1}$, Ines Schroeder ${ }^{1}$, Gerhard Steinbeck ${ }^{1}$ and \\ Andreas Knez ${ }^{1}$
}

\begin{abstract}
Address: ${ }^{1}$ Department of Cardiology, Ludwig-Maximilians-University, Munich, Germany and ${ }^{2}$ Department of Clinical Radiology, LudwigMaximilians-University, Munich, Germany

Email: Alexander Becker* - alexander.becker@med.uni-muenchen.de; Alexander W Leber - alexander.leber@med.uni-muenchen.de; Christoph Becker - christoph.becker@med.uni-muenchen.de; Franz von Ziegler - franz.ziegler@med.uni-muenchen.de; Janine Tittus - janine.tittus@med.uni-muenchen.de; Ines Schroeder - ines.schroeder@med.uni-muenchen.de;

Gerhard Steinbeck - gerhard.steinbeck@med.uni-muenchen.de; Andreas Knez - andreas.knez@med.uni-muenchen.de

* Corresponding author
\end{abstract}

Published: 10 October 2008

BMC Cardiovascular Disorders 2008, 8:27 doi:10.1186/147/-226I-8-27

This article is available from: http://www.biomedcentral.com/|47|-226I/8/27

(c) 2008 Becker et al; licensee BioMed Central Ltd.

This is an Open Access article distributed under the terms of the Creative Commons Attribution License (http://creativecommons.org/licenses/by/2.0), which permits unrestricted use, distribution, and reproduction in any medium, provided the original work is properly cited.
Received: 12 May 2008
Accepted: 10 October 2008

\begin{abstract}
Background: To establish an efficient prophylaxis of coronary artery disease reliable risk stratification is crucial, especially in the high risk population of patients suffering from diabetes mellitus. This prospective study determined the predictive value of coronary calcifications for future cardiovascular events in asymptomatic patients with diabetes mellitus.
\end{abstract}

Methods: We included 716 patients suffering from diabetes mellitus (430 men, 286 women, age $55.2 \pm$ 15.2 years) in this study. On study entry all patients were asymptomatic and had no history of coronary artery disease. In addition, all patients showed no signs of coronary artery disease in ECG, stress ECG or echocardiography. Coronary calcifications were determined with the Imatron C I50 XP electron beam computed tomograph. For quantification of coronary calcifications we calculated the Agatston score. After a mean observation period of $8.1 \pm \mathrm{I}$.I years patients were contacted and the event rate of cardiac death $(\mathrm{CD})$ and myocardial infarction (MI) was determined.

Results: During the observation period 40 patients suffered from MI, 36 patients died from acute CD. The initial Agatston score in patients that suffered from MI or died from CD $(475 \pm 208)$ was significantly higher compared to those without cardiac events $(236 \pm 199, p<0.01)$. An Agatston score above 400 was associated with a significantly higher annualised event rate for cardiovascular events $(5.6 \%$ versus $0.7 \%, P$ $<0.01$ ). No cardiac events were observed in patients with exclusion of coronary calcifications. Compared to the Framingham risk score and the UKPDS score the Agatston score showed a significantly higher diagnostic accuracy in the prediction of MI with an area under the ROC curve of 0.77 versus 0.68 , and $0.7 \mathrm{I}$, respectively, $\mathrm{p}<0.01$.

Conclusion: By determination of coronary calcifications patients at risk for future $\mathrm{MI}$ and $\mathrm{CD}$ could be identified within an asymptomatic high risk group of patients suffering from diabetes mellitus. On the other hand future events could be excluded in patients without coronary calcifications. 


\section{Background}

Diabetes mellitus is one of the most common diseases in the industrialized countries. The prevalence is expected to rise over $5 \%$ in the next 10 years [1]. Thereby patients with diabetes mellitus show an increased risk of cardiovascular events [2]. Independent of concomitant cardiovascular risk factors diabetic patients possess an up to fourfold risk of cardiovascular events, equivalent to the risk of nondiabetic patients with a history of coronary artery disease [3]. In addition, the fatality rate of CAD is significantly higher in diabetic patients [4]. Overall 65\% of diabetic patients die because of cardiovascular diseases.

To assess the risk of future events in this high risk population, several score systems based on concomitant risk factors and diseases have been introduced. Thereby the diagnostic accuracy in the prediction of future events is still limited [5-7]. Beside the scores based on epidemiological studies electron beam computed tomography offers the possibility to detect and quantify the amount of coronary calcium (CAC). In histopathologic studies coronary calcifications have shown to be a sensitive marker of early stages of coronary atherosclerosis [8,9]. Furthermore, the amount of coronary calcifications correlates to the extent of coronary atherosclerosis and coronary stenosis $[10,11]$. Several studies have already shown the association of future cardiovascular events with an elevated amount of coronary calcifications. In addition, the exclusion of coronary calcification is associated with a strong negative predictive value for future cardiovascular events. Still it is questionable, whether the determination of CAC adds an additional prognostic and clinical value in a high risk population of patients [12-14]. Therefore, we concentrated in this prospective study on asymptomatic patients suffering from diabetes mellitus and assessed the prognostic value of CAC over an observation period of 8 years. In addition, the results were compared to conventional models of risk stratification, the Framingham cardiovascular risk score, and the UKPDS risk engine $[5,15]$.

\section{Methods \\ Study protocol}

The research protocol was approved by the local Clinical Institutional Review Board and complies with the declaration of Helsinki. From January 1998 to April 1999 we asked 938 asymptomatic patients with Diabetes mellitus type 2 referred to our clinic for a preventive medical check up to take part in this prospective study. 776 patients agreed to undergo EBCT scanning and follow up-interview and were included in this study after giving written consent. All patients had no history of CAD and were asymptomatic regarding $\mathrm{CAD}$. In addition no signs of CAD could be found in ECG, stress ECG and echocardiography. Thereby Stress ECG was not available in 18 patients, echocardiography in 12 patients.

\section{Risk factors}

Diagnosis of diabetes mellitus was assured in all patients by determination of glucose in fasting state as described by the definition of the World Health Organization [16]. Additional cardiovascular risk factors were assessed by personal interview and screening of medical records. In every patient arterial blood pressure (three times after 10 minutes rest), LDL cholesterol level, HDL cholesterol level, and triglyceride level were determined in the fasting state in our hospital. Arterial hypertension was defined as systolic blood pressure above $140 \mathrm{mmHg}$ or diastolic blood pressure above $90 \mathrm{mmHg}$. Family history was measured by personal interview and defined as coronary heart disease in male first degree relative $<55$ years; coronary heart disease in female first degree relative $<65$ years.

Based on cardiovascular risk factors and concomitant diseases we calculated the risk for future cardiac death or nonfatal myocardial infarction based on the Framingham population and the UKPDS risk engine [17]. According to both scores patients were assigned to one of the following risk groups: low risk (event rate $<10 \%$ ), intermediate risk (event rate $>10 \%$ and $<20 \%$ ), and high risk (event rate $>$ $20 \%$ ).

\section{EBCT scanning procedure}

EBCT scans were performed using the Imatron C-150 XP scanner (Imatron, South San Francisco, California, USA) in the high resolution mode. Images were acquired ECGtriggered at 80 percent of the R-R interval during one endinspiratory breathholding period. Slice thickness was 3 $\mathrm{mm}$, scan time $100 \mathrm{~ms}$. A field of view of $26 \mathrm{~cm}$ was chosen. A total of 40 slices were obtained covering the whole heart. Coronary calcifications were defined as lesions with a density $>130 \mathrm{HU}$ in more than 2 adjacent pixels. For quantification of coronary calcium we calculated the Agatston score, which is the product of the lesions area and a factor from 1 to 4 representing the peak density of the lesion [18]. EBCT scans were evaluated without knowledge of patient's characteristics. The patients were unaware of their Agatston score.

\section{Clinical follow-up}

Study patients were contacted after an observation time of 8 years after the CT scan. An interims analysis was performed after 4 years. Cardiovascular events were assessed using a standardized telephone interview. In case of hospital admission or further cardiologic examinations the patient's medical records were reviewed for complaints of chest discomfort, dyspnea, myocardial infarction, and coronary revascularization.

\section{Clinical endpoints}

The study endpoints were cardiac death (CD) and myocardial infarction (MI) as hard events and coronary revas- 
cularization (CR), coronary artery bypass graft (CABG) or percutaneous transluminal coronary angioplasty (PTCA), as soft events. MI was defined as the presence of at least 2 of the following: prolonged chest pain leading to hospital admission, specific ECG changes, elevation of serum creatine kinase levels up to twice the upper limit with an elevated creatine kinase-MB fraction or troponin level. Death due to coronary artery disease was considered when death was proved to be due to coronary atherosclerosis by autopsy, occurred within 1 hour after onset of prolonged severe chest pain, or occurred during hospital admission because of MI. Coronary interventions had to be confirmed by reports of the performing physician.

\section{Statistics}

Statistical analyses were performed using the SPSS software package (version 10.0, SPSS Inc. Chicago, Illinois). Agatston score was expressed as mean score \pm standard deviation except where indicated. Because of the non-normality, statistical analysis was performed on the base 10 $\log$ of the transformed Agatston score +1 . To compare score values in different risk groups, we used the Wilcoxon signed rank test for unpaired data. A p-value under 0.05 was considered to indicate statistical significance. We performed univariate Cox regression analysis to calculate hazard ratio and 95 percent confidence interval of cardiac death and MI in dependence of cardiovascular risk factors (patients without cardiovascular risk factors served as the reference group), age, sex, and Agatston score (patients without coronary calcifications served as the reference group). To account for the inflation of the type I error due to multiple testing, we performed the Bonferroni adjustment. The significance level was set at $0.05 / 4=0.0125$ and $0.05 / 2=0.025$.

In addition, Cox proportional hazards survival curves showing the estimated event free survival determined by the Cox regression model were calculated for patients in different score categories [19]. The results were adjusted for differences in age and sex. To verify the assumption of proportional hazards we performed an analysis of the Kaplan-Meier curves as described by Hosmer and Lemeshow.

To demonstrate the discriminatory power of Agatston score, UKPDS score, and Framingham score in prediction of cardiovascular events the area under the receiver-operating characteristic (ROC) curve was determined. ROC curve analysis was performed as follows: Sensitivity was plotted as a function of the false positive rate (1-specificity) for predicting cardiovascular events. An area under the curve of 1.0 represents a perfect test with 100 percent sensitivity and 100 percent specificity, whereas an area of 0.5 represents a random discrimination. Areas under the curve above 0.7 might indicate a reasonably good clinical test in combination with a sufficient diagnostic accuracy (sensitivity, specificity, negative and positive predictive value). Different ROC curves were compared using the method of Hanley and McNeil [20].

\section{Results}

716 individuals (430 men and 280 women, age $55.2 \pm$ 15.2 years) of the initially 776 included patients completed the follow up. 32 patients died of non-cardiac death, 28 patients could not be contacted for a follow-up examination. There was no difference in age, risk factor distribution, and Agatston score between these patients that completed the follow up and those that did not finish the study. The mean observation time was $8.1 \pm 1.1$ years (range 7.1 to 9.4 years). Patients' characteristics and therapies are given in table 1 . The mean number of risk factors per person was $3.0 \pm 1.3$ in men and $2.8 \pm 1.1$ in women (range $1-5$ ), see table 1 .

\section{Distribution of Agatston score}

The mean Agatston score was $288 \pm 153$ (range $0-2849$, median 576, quartile rank 145 and 877), $319 \pm 187$ for men, and $241 \pm 157$ for women, $\mathrm{p}=0.02$. The score increased from $34 \pm 11$ (range 0 - 99) for patients under 40 years to $418 \pm 178$ (range $0-2849$ ) for patients older than 70 years. In 107 patients coronary calcifications could be excluded (score 0), 302 patients showed an Agatston score above 400. In all age groups the mean score in men was significantly higher than in women. In patients with additional arterial hypertension $(252 \pm 160$, range 0 $-701, \mathrm{p}=0.03)$, and hyperlipidemia $(439 \pm 256$, range 0 - 699, $p=0.01$ ) the average Agatston score was significantly higher than in patients without additional cardiovascular risk factors $(124 \pm 74$, range $0-430)$.

\section{Cardiac events}

36 patients died from CD $(0.6 \%$ annualised rate $), 40$ patients suffered from MI (0.7\% annualised rate) and 87 patients (64 patients PTCA and 23 patients CABG) underwent coronary revascularization (1.5\% annualised rate). There was no significant difference between men and women in all event rates, $\mathrm{p}=0.12$

No patient with exclusion of cardiovascular calcifications suffered from MI or CD during the observation period, only two patients with exclusion of coronary calcifications underwent coronary revascularization. The event rates of patients with exclusion of coronary calcifications were significantly lower compared to patients with coronary calcifications, $\mathrm{p}=0.009$, see table 2 . In patients with scores above 400 the annualised rates were significantly higher for all events $(p=0.011)$.

Figure 1 shows the association between calcium score categories and event free survival, the results were adjusted 
Table I: Baseline characteristics of 716 patients included in the study

\begin{tabular}{|c|c|c|c|}
\hline & all & men & women \\
\hline number $(n)$ & 716 & 430 & 286 \\
\hline age (years) & $55.2 \pm 15.2$ & $55.5 \pm 15.2$ & $54.8 \pm 15.2$ \\
\hline no additional risk factor, $\mathrm{n}(\%)$ & $143(20)$ & $83(20)$ & $60(2 \mathrm{I})$ \\
\hline arterial hypertension, $\mathrm{n}(\%)$ & $372(52)$ & $249(58)$ & $123(43)$ \\
\hline treated, $\mathrm{BP}<140 / 90 \mathrm{n}(\%)$ & $125(17)$ & $77(18)$ & $48(17)$ \\
\hline treated, BP > 140/90 n (\%) & $140(20)$ & $96(22)$ & $44(15)$ \\
\hline untreated, BP > 140/90 n (\%) & $107(15)$ & $76(18)$ & $31(11)$ \\
\hline hyperlipidemia or statin therapy, n (\%) & $301(42)$ & $184(44)$ & $117(4 I)$ \\
\hline statin therapy, cholesterol $<5 \mathrm{mmol} / \mathrm{l} \mathrm{n}(\%)$ & $99(14)$ & $61(14)$ & $38(13)$ \\
\hline statin therapy, cholesterol $>5 \mathrm{mmol} / \mathrm{l} \mathrm{n}(\%)$ & $124(17)$ & $70(16)$ & $54(19)$ \\
\hline untreated, cholesterol > $5 \mathrm{mmol} / \mathrm{l} \mathrm{n}(\%)$ & $78(\mathrm{II})$ & $53(12)$ & $25(9)$ \\
\hline MI in family history, $\mathrm{n}(\%)$ & $451(63)$ & $271(63)$ & $186(65)$ \\
\hline smoking, n (\%) & $243(34)$ & $15 \mid(35)$ & $94(33)$ \\
\hline HbAlc (\%) & 7.5 & 7.6 & 7.5 \\
\hline average number of risk factors & 2.9 & 3.0 & 2.8 \\
\hline body mass index $\left(\mathrm{kg} / \mathrm{m}^{2}\right)$ & $27.1 \pm 6.1$ & $28.3 \pm 5.8$ & $25.0 \pm 4.9$ \\
\hline duration of Diabetes (years) & $6.5 \pm 2.3$ & $6.4 \pm 2.2$ & $6.6 \pm 2.3$ \\
\hline microalbuminuria n (\%) & $64(9)$ & $41(9)$ & $23(8)$ \\
\hline proteinuria $\mathrm{n}(\%)$ & $41(6)$ & $25(6)$ & $16(6)$ \\
\hline peripheral neuropathy n (\%) & $104(15)$ & $60(14)$ & $44(15)$ \\
\hline retinopathy $\mathrm{n}(\%)$ & $145(20)$ & $90(21)$ & $55(19)$ \\
\hline atrial fibrillation $\mathrm{n}(\%)$ & $95(13)$ & $61(14)$ & $24(12)$ \\
\hline insulin only $\mathrm{n}(\%)$ & $105(15)$ & $62(15)$ & $43(15)$ \\
\hline insulin + oral agent $n(\%)$ & $109(15)$ & $70(16)$ & $39(14)$ \\
\hline oral agent only $\mathrm{n}(\%)$ & $502(70)$ & $298(69)$ & $204(7 I)$ \\
\hline
\end{tabular}

for differences in age and sex. The cumulative incidence increased continuously form $3.9 \%$ for patients with scores between $0-10$ to a cumulative incidence of $42.7 \%$ for patients with scores above 400 .

\section{Scores in patients with $\mathrm{MI}$ or CD}

The mean Agatston score of patients that died from CD or suffered from MI was significantly higher than in patients without cardiovascular events, $475 \pm 208$ compared to $236 \pm 199, p=0.009$. In addition, patients that underwent
CR showed a significantly higher Agatston score of $447 \pm$ 228 compared to patients without cardiac event, $236 \pm$ $199, \mathrm{p}=0.007$. Framingham risk score and UKPDS score were significantly higher in patients with cardiovascular events. There was no significant difference in age or average number of risk factors between patients with or without cardiac events (table 2).

Figure 2 depicts the distribution of Framingham score, UKPDS score, and Agatston score in patients with MI.

Table 2: Event rates for coronary revascularisation (CR), myocardial infarction (MI), and cardiac death (CD) in all patients, patients with Agatston score 0, and Agatston score above 400: Total number of events during observation period and annualised rate

\begin{tabular}{|c|c|c|c|c|c|c|c|c|}
\hline & \multirow{2}{*}{$\begin{array}{c}\text { All patients } \\
\mathrm{n}\end{array}$} & \multirow{2}{*}{$\begin{array}{c}\text { no event } \\
n\end{array}$} & \multicolumn{2}{|c|}{$C R$} & \multicolumn{2}{|c|}{$M I+C D$} & \multicolumn{2}{|c|}{ all events } \\
\hline & & & $\mathrm{n}$ & $\%$ per year & $\mathrm{n}$ & $\%$ per year & $\mathrm{n}$ & $\%$ per year \\
\hline Patients (n) & 716 & 553 & 87 & 1.5 & 76 & 1.3 & 163 & 2.8 \\
\hline men $(n)$ & 430 & 332 & 53 & 1.5 & 45 & 1.3 & 98 & 2.8 \\
\hline Women (n) & 286 & 224 & 31 & 1.3 & 31 & 1.3 & 62 & 2.7 \\
\hline Score 0 & 107 & 105 & 2 & 0.2 & 0 & 0.0 & 2 & 0.2 \\
\hline Score $>400$ & 302 & 165 & 71 & $2.9 *$ & 66 & $2.7 *$ & 137 & $5.6 *$ \\
\hline number of risk factors & 2.9 & 2.7 & 2.8 & & 2.9 & & 2.9 & \\
\hline age (years) & $55.7 \pm 13.0$ & $55.3 \pm 13.2$ & $57.4 \pm 12.4$ & & $56.9 \pm 13.1$ & & $57.1 \pm 12.9$ & \\
\hline Agatston score & $288 \pm 153$ & $236 \pm 199$ & $447 \pm 228 *$ & & $475 \pm 208 *$ & & $459 \pm 219 *$ & \\
\hline Framingham risk score & $9.6 \pm 3.4$ & $8.6 \pm 3.4$ & $13.1 \pm 3.9 *$ & & $13.7 \pm 4.1 *$ & & $13.3 \pm 3.8 *$ & \\
\hline UKPDS Score & $9.6 \pm 2.8$ & $8.4 \pm 3.6$ & $13.7 \pm 4.0 *$ & & $14.0 \pm 4.3 *$ & & $13.8 \pm 4.1 *$ & \\
\hline
\end{tabular}

Score parameters (UKPDS score, Framingham score, and Agatston score) in patients with and without cardiovascular events * indicates a significant higher event rate and a significant difference in score, respectively, $\dagger$ indicates a significant lower event rate $(p<0.05)$ compared to the event rate in all patients (first row). 


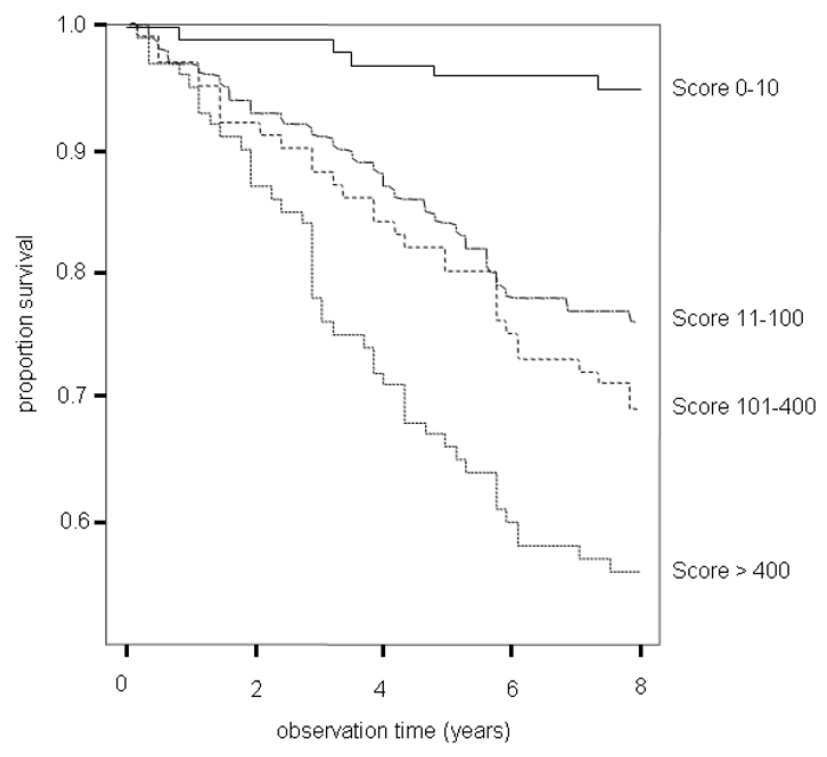

Figure I

Cox proportional hazards survival curves showing the cumulative event free survival for patients with scores from $0-10,11-100,101-400$, and above 400 .

According to Framingham score (57\%) and UKPDS score $(60 \%)$ most patients with MI were considered as intermediate risk patients. $34 \%$ and $36 \%$, respectively, were assigned to the high risk group. 9\% (Framingham score) and $4 \%$ (UKPDS score) of patients with MI would have been considered as low risk patients. The proportion of patients with MI and an Agatston score above the $75^{\text {th }}$ percentile added up to $86 \%, 13 \%$ had an Agatston score below the $75^{\text {th }}$ and above the $25^{\text {th }}$ percentile, and $1 \%$ had an Agatston score below the $25^{\text {th }}$ percentile.

\section{Relative Risk of MI}

The relative risk for MI and CD in dependence of additional cardiovascular risk factors was lowest for patients with smoking, 2.14, and increased with 2.47 for patients with arterial hypertension up to 2.75 for patients with hyperlipidemia. The relative risk for MI and CD was increased in patients with diabetes associated diseases, 1.76 in patients with retinopathy, 1.36 in patients with microalbuminuria, and 1.76 in patients with proteinuria. An increase of Framingham score and UKPDS score was associated with an increase of relative risk, 6.0 for a ten unit increase of Framingham score and 7.1 for a ten unit increase of UKPDS score. The highest relative risk of 14.2 for MI or CD was calculated for patients with Agatston scores above 400 (table 3 ). In addition table 4 shows the relative risk of cardiovascular events for different categories of calcifications: We found a continuously increasing risk of cardiovascular events with increasing calcium scores, the relative risk increased from 3.1 (2.8 women)

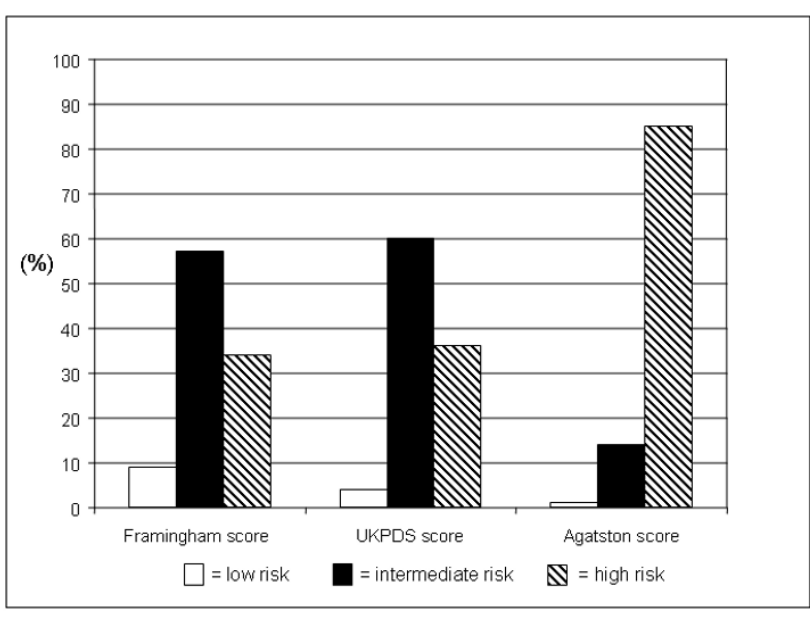

Figure 2

Risk stratification according to UKPDS score, Framingham score, and Agatston score in patients suffering from myocardial infarction $(n=76)$.

for patients with scores from 0 - 10 to 32.8 (50.0 women) for patients with scores above 400 .

To illustrate the diagnostic accuracy of UKPDS score, Framingham score and Agatston score for the prediction of MI, ROC curves were calculated and the area under the ROC curve representing the diagnostic threshold was determined. The area under the ROC curve of the Agatston score was significantly larger than the area under the ROC curves of UKPDS score and Framingham score $(0.76$, confidence interval $0.73-0.82$, compared to 0.63 , confi-

Table 3: Univariable Cox proportional hazards model predicting the combined primary endpoint myocardial infarction and cardiac death (MI and $C D$ ) in dependence of cardiovascular risk factors and Agatston scores above the 75. percentile

\begin{tabular}{cccc}
\hline & relative risk & $95 \% \mathrm{Cl}$ & $\mathrm{P}$ value \\
\hline no risk factors & $\mathrm{I}$ & - & - \\
arterial hypertension & $2.47 *$ & $2.21-2.8 \mathrm{I}$ & 0.005 \\
smoking & $2.14 *$ & $2.01-2.33$ & 0.005 \\
hyperlipidemia & $2.75 *$ & $2.49-3.19$ & 0.006 \\
microalbuminuria & 1.36 & $1.30-1.47$ & 0.151 \\
proteinuria & $1.71 *$ & $1.56-1.97$ & 0.018 \\
familiy history & $1.45 *$ & $1.28-1.73$ & 0.012 \\
duration of diabetes & 1.51 & $1.39-1.69$ & 0.013 \\
retinopathy & $1.76 *$ & $1.60-2.04$ & 0.013 \\
HbAIC & $1.89 *$ & $1.69-2.19$ & 0.009 \\
Framingham risk score & $6.0 *$ & $4.9-7.8$ & 0.004 \\
UKPDS Score & $7.1 *$ & $6.0-8.9$ & 0.003 \\
Agatston score $>400$ & $14.2 *$ & $12.7-16.8$ & 0.001
\end{tabular}

* indicates a significant difference $(\mathrm{p}<0.05)$ compared to the patient group without cardiovascular risk factors and without coronary calcifications, respectively. 
Table 4: Cox proportional hazards model predicting the combined primary endpoint (MI and CD) in different score groups for men a) and women b) adjusted for cardiovascular risk factors

\begin{tabular}{|c|c|c|c|c|c|}
\hline \multicolumn{6}{|l|}{ a) men } \\
\hline Score & number of events & number of patients & event rate (\%) & hazard ratio $(95 \% \mathrm{Cl})$ & $P$ value \\
\hline $0-10$ & 2 & 63 & 3.1 & I & \\
\hline $11-100$ & 8 & 80 & 10.0 & $1.9(1.5-2.5) *$ & 0.04 \\
\hline $101-400$ & 23 & 86 & 26.7 & $5.4(4.5-7.0) *$ & 0.02 \\
\hline$>400$ & 66 & 201 & 32.8 & $9.5(8.0-11.9) *$ & 0.01 \\
\hline All & 99 & 430 & 10.8 & & \\
\hline \multicolumn{6}{|l|}{ b) women } \\
\hline Score & number of events & number of patients & event rate $(\%)$ & hazard ratio $(95 \% \mathrm{Cl})$ & $P$ value \\
\hline $0-10$ & I & 74 & 2.8 & I & \\
\hline $11-100$ & 5 & 82 & 6.1 & $1.6(1.1-2.3) *$ & 0.02 \\
\hline $101-400$ & 22 & 60 & 36.7 & $5.2(4.0-6.9) *$ & 0.02 \\
\hline$>400$ & 35 & 70 & 50.0 & $14.1(12.0-16.8) *$ & 0.01 \\
\hline All & 62 & 286 & 9.9 & & \\
\hline
\end{tabular}

* indicates a significant difference $(\mathrm{p}<0.05)$ compared to the patient group without coronary calcifications.

dence interval $0.59-0.66$, and 0.66 , confidence interval $0.62-0.68, \mathrm{p}=0.03$, figure 3 )

\section{Discussion}

The aim of this study was to evaluate the predictive value of coronary calcifications in a high risk population, patients suffering from diabetes, over a long-term observation period of 8 years. The results were compared to conventional risk stratification using Framingham score and UKPDS score. On study entry all patients were not only asymptomatic, but also showed negative results in ECG, stress ECG, and echocardiography. Thus, further diagnostics or interventions were not indicated following the present guidelines and the study population could be considered a homogenous collective without evidence of coronary artery disease on study entry.

The distribution of risk factors and diabetes associated diseases is similar to study populations in prior studies examining cardiovascular risk stratification in patients with diabetes mellitus $[16,21]$. Compared to prior studies evaluating the predictive value of coronary calcifications the number of risk factors per person is increased, which can be explained by the preselection due to concentrating on patients with diabetes referred for a cardiological examination $[12,13,22]$.

\section{Distribution of coronary calcifications}

It has been discussed, if cardiovascular risk stratification can be improved by determination of coronary calcium in populations with an already increased risk for cardiovascular events such as patients with diabetes mellitus or elderly patients. The average score of $288 \pm 153$ in this study was higher compared to non-diabetic populations described by Hoff et al., Rumberger et al., and Schmer- mund et al. [23,24,22]. Still we could find a similar score distribution within our population: As described in several previous publications the mean Agatston score

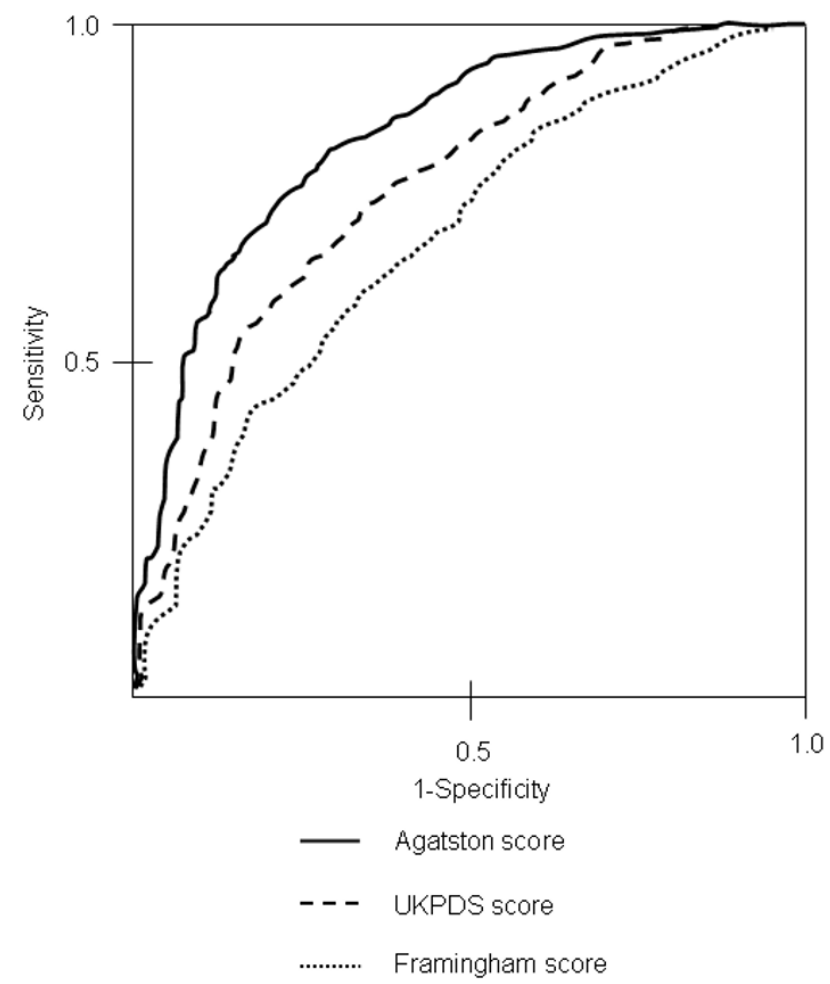

Figure 3

ROC curves and area under the curve of UKPDS score, Framingham score, and Agatston score for the prediction of myocardial infarction. 
increased with patients' age and was significantly higher in male than in female patients. As expected, an increase of coronary calcifications in patients with additional cardiovascular risk factors could be observed. Within these subgroups a further discrimination of patients by calcium score was possible: In each group patients with a score of zero could be found, whereas in patients without additional risk factors scores up to 430 could be detected. These findings comply not only with studies in non-diabetic populations $[25,12]$, but a similar score distribution could be found in other studies examining patients with an elevated risk of cardiovascular event and elevated calcium scores: Vliegenthart et al. achieved equivalent results in elderly patients, Anand et al. in diabetic patients $[26,21]$.

Therefore, an additive value of coronary calcium for an improved risk stratification can be assumed in diabetic individuals.

\section{Cardiovascular events}

This assumption is being supported by the significantly higher event rate for CR, MI, and CD of patients with an Agatston score above 400. In addition future MI or CD could be excluded in patients without coronary calcifications (table 2). This could be observed independently of concomitant risk factors in all age groups indicating that coronary calcifications reflect the patient's individual extent of atherosclerosis. Therefore, coronary calcifications can be considered as an adequate tool for the individual prediction of cardiovascular events and might be superior to conventional risk stratification.

The high accuracy of coronary calcifications is expressed by the score distribution in patients that suffered from MI during the observation period. Although we found significantly higher Framingham scores and UKPDS scores in patients with MI the risk stratification using the Agatston score was superior to Framingham score and UKPDS score: Whereas only $34 \%$ and $36 \%$ of patients with MI were classified as high risk patients according to Framingham score and UKPDS score, $85 \%$ of patients with MI were considered as high risk patients according to Agatston score. Most patients with MI, 57\% and $60 \%$, were classified as patients with an intermediate risk by Framingham score and UKPDS score. The score distribution in patients with MI was thereby comparable to prior studies in non-diabetic populations examined by Achenbach et al. and Becker et al. [12,25].

The strong correlation between coronary calcium and future cardiovascular events is also expressed by the increasing relative risk in different score groups. The relative risk in dependence of elevated Agatston score levels was significantly higher than the relative risk of conven- tional cardiovascular risk factors, diabetes associated diseases, or Framingham and UKPDS score (see table 3 and $4)$.

The high diagnostic accuracy of the Agatston score is also shown by the high negative predictive value: In all 107 patients with exclusion of coronary calcifications future cardiovascular events could be excluded. Thus, the present study with a long-term observation period in diabetic individuals could confirm the results in prior studies by Greenland et al, Achenbach et al., and Anand et al. $[27,12,21]$.

In addition, the significantly higher discriminatory power of the Agatston score for the prediction of $\mathrm{MI}$ is shown by the significantly larger area under the ROC curve of the Agatston score compared to Framingham and UKPDS score ( 0.76 versus 0.63 and. 0.66 , respectively, $\mathrm{p}=0.03$ ).

\section{Limitations}

The study population consisted of patients with diabetes sent to our institution for a preventive medical check up. Therefore, the collective can not be considered as an unselected population. Still it can be regarded as a homogenous population without signs of CAD on study entry, as ECG, stress ECG, and echocardiography showed regular findings. All patients received an equivalent treatment according to current guidelines. And it might be just these patients with diabetes mellitus sent for further diagnostics that profit most from improved risk stratifications.

Even if the exclusion of future cardiovascular events by exclusion of coronary calcifications seems to be possible, it is still questionable, whether a reduction of the current prophylactic therapy in these patients is advisable. Rather a reduction of further examinations e.g. myocardial scintigraphy or coronary angiography could result from an exclusion of coronary calcifications.

Still it has to be determined, whether the detection of coronary calcification can help to establish more efficient therapies and diagnostics in patients with diabetes.

This study was performed using the EBCT, which is hardly available today. It has already been shown, that an equivalent quantification of coronary calcifications is possible by multislice computed tomography $[28,29]$.

\section{Conclusion}

Within a diabetic population, patients with a high risk for future MI and CD could be identified by the determination of coronary calcifications independent of concomitant cardiovascular risk factors. Thereby the Agatston score showed a higher diagnostic accuracy in predicting MI compared to Framingham risk score or UKPDS risk score. 
The exclusion of coronary calcifications allowed the exclusion of future cardiovascular events within a long term observation period of 8 years.

\section{Competing interests}

The authors declare that they have no competing interests.

\section{Authors' contributions}

$\mathrm{AB}$ is responsible for coordination of the study, statistical evaluation and manuscript. AL is responsible for the evaluation of coronary calcifications. CB performed EBCT scanning. FZ, JT, and IS performed examinations on study entry and follow up interviews. GS is responsible for manuscript review. AK is responsible for coordination of the study.

\section{References}

I. King $\mathrm{H}$, Aubert RE, Herman $\mathrm{WH}$ : Global burden of diabetes 1995-2025: prevalence, numerical estimates and projections. Diabetes Care 1998, 2 I :|4|4-3|

2. Nathan DM, Meigs J, Singer DE: The epidemiology of cardiovascular disease in type 2 diabetes mellitus: how sweet it is ... or is it? Lancet I997, 350(Suppl I):4-9.

3. Juutilainen A, Lehto S, Rönnemaa T, Pyörälä K, Laakso M: Type 2 diabetes as a'coronary heart disease equivalent': an I8-year prospective population-based study in Finnish subjects. Diabetes Care 2005, 28:2901-7.

4. Meigs JB: Epidemiology of cardiovascular disease in type II diabetes mellitus. Acta Diabetol 2003, 40:S358-6I.

5. Anderson KM, Castelli WP, Levy D: Cholestrol and mortality: $\mathbf{3 0}$ years of follow-up from the Framingham study. JAMA 1987 257:2176-80.

6. Guzder RN, Gatling W, Mullee MA, Mehta RL, Byrne CD: Prognostic value of the Framingham cardiovascular risk equation and the UKPDS risk engine for coronary heart disease in newly diagnosed Type $\mathbf{2}$ diabetes: results from a United Kingdom study. Diabet Med 2005, 22:554-62.

7. Akosah KO, Schaper A, Cogbill C, Schoenfeld P: Preventing myocardial infarction in the young adult in the first place: how do the National Cholsterol Education Panel III guidelines perform? J Am Coll Cardiol 2003, 4 I: : 475-9.

8. Rumberger JA, Simons DB, Fitzpatrick LA, Sheedy PF, Schwartz RS: Coronary artery cacium area by electronbeam computed tomography and coronary atherosclerotic plaque area: a histopathologic correlative study. Circulation 1995, 92:2157-62.

9. Mautner GC, Mautner SL, Froehlich J, Feuerstein IM, Proschan MA Roberts WC, Doppman JL: Coronary artery calcification: assessment with electron beam computed tomography and histomorphometric correlation. Radiology 1994, 192:619-23.

10. Rumberger JA, Sheedy PF, Breen JF, Schwartz RS: Electron beam computed tomographic coronary calcium score cutpoints and severity of associated angiographic lumen stenosis. J Am Coll Cardiol 1997, 29: I542-8.

II. Haberl R, Becker A, Leber A, Knez A, Becker C, Lang C, Brüning R Reiser M, Steinbeck G: Correlation of Coronary Calcification and Angiographically Documented Stenoses in Patients With Suspected Coronary Artery Disaese: Results of 1764 Patients. J Am Coll Cardiol 2001, 37:451-7.

12. Achenbach S, Nomayo A, Couturier G, Ropers D, Pohle K, Schlundt C, Schmermund A, Matarazzo TJ, Hoffmann U, Daniel WG, Killip T: Relation Between Coronary Calcium and I0-Year Risk Scores in Primary Prevention Patients. Am J Cardiol 2003, 92: $|47|-5$

13. Kondos G, Hoff J, Sevrukov A, Daviglus ML, Garside DB, Devries SS, Chomka EV, Liu K: Electron-Beam Computed Tomography Coronary Calcium and Cardiac Events A 37-month FollowUp of 5635 Initially Asymptomatic Low- to IntermediateRisk Adults. Circulation 2003, 107:257|-6.

14. Detrano RC, Wong ND, Doherty TM, Shavelle RM, Tang W, Gintzon LE, Budoff MJ, Narahara KA: Coronary Calcium Does Not Accu- rately Predict Near-Term Future Coronary Events in HighRisk Adults. Circulation 1999, 99:2633-8.

15. Stratton IM, Alder AI, Neil HA, Matthewes DR, Manley SE, Cull CA, Hadden D, Turner RC, Holman RR: Association of glycaemia with macrovascular and microvascular complications of type II diabetes (UKPDS 35): a prospective observational study. BM] 2000, 32I:405-12.

16. World Health Organization: Definition, diagnosis and classification of diabetes mellitus and its complications. Part I. In Diagnosis and classification of diabetes mellitus Switzerland, Geneva: World Health Organization; 1999.

17. Wilson PW, D'Agostino RB, Levy D, Belanger AM, Silbershatz $\mathrm{H}$, Kannel WB: Prediction of coronary heart disease using risk factor catagories. Circulation 1999, 97: 1837-47.

18. Agatston AS, Janowitz WR, Hildner FJ, Zusmer NR, Viamonte M, Detrano R: Quantification of coronary artery calcium using ultrafast computed tomography. I Am Coll Cardiol 1990 I 5:827-32.

19. Marwick TH, Shaw LJ, Lauer MS, Kesler K, Hachamovitch R, Heller GV, TRavin MI, Borges-Neto S, Berman DS, Miller DD: The nonivasive prediction of cardiac mortality in men and women with known or suspected coronary artery disease. Economics of Noninvasive Diagnosis (END) Study Group. Am J Med I999, 106: 172-8.

20. Hanley JA, McNeil BJ: A method of comparing the areas under receiver operating characteristic curves dereives from the same cases. Radiology 1983, I48(3):839-43.

21. Anand DV, Lim E, Hopkins D, Corder R, Shaw LJ, Sharp P, Lipkin D, Lahiri A: Risk stratification in uncomplicated type 2 diabetes: prospective evaluation of the combined use of coronary artery calcium imaging and selective myocardial perfusion scintigraphy. Eur Heart J 2006, 26:7 I3-2I.

22. Schmermund A, Erbel R, Silber S, for the MUNICH Registry Study Group: Age and Gender Distribution of Coronary Artery Calcium Measured by Four-Slice Computed Tomography in 2.030 Persons with no Symptoms of Coronary Artery Disease. Am / Cardiol 2002, 90:168-73.

23. Hoff J, Daviglus M, Chomka EV, Krainik AJ, Sevkurov A, Kondos GT: Conventional Coronary Artery Disease Risk Factors and Coronary Artery Calcium Detected by Electron Beam Tomography in $\mathbf{3 0 . 9 0 8}$ Healthy Individuals. Ann Epidemiol 2003, 13:163-9.

24. Rumberger J, Kaufmann L: A Rosetta Stone for Coronary Calcium Risk Stratification: Agatston, Volume, and Mass Scores in 11.490 Indiviuals. AJR 2003, 181:743-8.

25. Becker A, Leber A, Becker C, Knez A: Predective value of coronary calcifications for future cardiac events in asymptomatic individuals. Am Heart / 2008, I 55: I54-60.

26. Vliegenthart R, Oudkerk M, Hofman A, Oei HH, van Dijck W, van Rooij FJ, Witteman JC: Coronary calcification improves cardiovascular risk prediction in the elderly. Circulation 2005, I I 2:572-7.

27. Greenland P, Labree L, Azen SP, Doherty TM, Detrano RC: Coronary Artery Calcium Score Combined With Framingham Score for Risk Prediction in Asymptomativ Individuals. JAMA 2004, 291:210-215.

28. Knez A, Becker C, Becker A, Leber A, White C, Reiser M, Steinbeck $\mathrm{G}$ : Determination of coronary calcium with multi-slice spiral computed tomography: a comparative study with electron beam CT. Int J Cardiovasc Imaging 2002, 18:295-303.

29. Becker CR, Kleffel T, Crispin A, Knez A, Young J, Schoepf UJ, Haberl R, Reiser MF: Coronary artery calcium measurement: agreement of multirow detector and electron beam CT. Am J Roentgenol 200I, I 76:1295-8.

\section{Pre-publication history}

The pre-publication history for this paper can be accessed here:

http://www.biomedcentral.com/1471-2261/8/27/prepub 